\title{
Impact of Exogenous Elicitors on Artemisinin Production and Trichome Density in Artemisia annua L. under Subtropical Conditions
}

\author{
Alka DANGASH ${ }^{1,2 *}$, Neeta PANDYA ${ }^{1}$, Ashish BHARILLYA ${ }^{2}$, Ashween JHALA ${ }^{2}$, \\ Dharamchand JAIN ${ }^{2}$ \\ ${ }^{1}$ Department of Botany, Faculty of Science, The Maharaja Sayajirao University of Baroda, Vadodara 390 002, Gujarat, India; \\ alkadj@gmail.com (*orresponding author) \\ ${ }^{2}$ Ipca Laboratories Ltd, Sejavta, Ratlam 457002, Madhya Pradesh, India
}

\begin{abstract}
Artemisinin is a sesquiterpene lactone found in Artemisia annua having many medicinal properties. Therefore the factors affecting trichome initiation are important. In the present study, several strategies have been adapted to increase artemisinin production by treating them with nutrients, hormones and elicitors. Abscisic acid, Gibberellic acid $\left(\mathrm{GA}_{3}\right)$, a combination of $\mathrm{GA}_{3}+\mathrm{IAA}$ (Gibberellic acid+indole acetic acid), Chitosan, Methyl jasmonate, Acetyl salicylic acid, Lead acetate, sodium chloride, and Nanozime were sprayed on plant at regular intervals. The glandular trichomes of leaves from Artemisia annua (Asteraceae) were examined by light and scanning electron microscopy and the percentage artemisnin content was analyzed by HPTLC. Maximum artemisinin content \% and trichome index (0.128) was found when methy jasmonate was applied and minimum artemisinin content $\%$ and trichome index was reported in $\mathrm{NaCl} \&$ acetyl salicylic acid.
\end{abstract}

Keywords: Artemisia, artemisinin, sesquiterpene, terpenoids, trichome

\section{Introduction}

Trichomes are specialized hairs that have evolved for a variety of functions. Trichomes are derived from epidermal cells and perform a wide range of functions. Some secrete sticky exudates to trap insects, others produce essential oil to attract beneficial insects or repel pests (Wang et al., 2001). Their presence can also modulate air flow over the leaf surface affecting respiration and transpiration rates. Trichomes also possess a chemical defense function as they accumulate a vast array of bioactive chemicals in many plants (Bhakuni et al., 2001; Turner and Croteau, 2004).

Trichomes have been of considerable importance in comparative investigation in angiosperms. They are frequently present, easily observable and have often been found to have varying patterns which correlate with other features of the taxa as under investigation (Cutler, 1969). There are two main types of trichomes: glandular and nonglandular trichomes. Glandular trichome secretes a mixture of chemicals that have been found to have an enormous array of uses in the pesticides, pharmaceutical and flavor industries (Duke and Paul, 1993; Ferreira et al., 1997).

Asteraceae is one of the highly important medicinal families consisting of a wide range of plants. A. annua is an herb originated in China. It has now been introduced and grown in many countries including Argentina, Bulgaria, France, Hungary, Romania, Italy, Spain, the United States, and former Yugoslavia (Klayman, 1989; Klayman, 1993). It is a highly aromatic plant can grow up to 2 meters tall and possesses many $2.5-5.0 \mathrm{~cm}$ long, deeply dissected leaves on alternating branches. Artemisia genus has 400 members which are biennial and perennial but $A$. annua is an annual plant. Artemisinin or Qinghaosu is the active constituent of the herb $A$. annua. Artemisinin is used in the treatment of drug-resistant Plasmodium falciparum malaria (Abdin et al., 2003). In China, $A$. annua $\mathrm{L}$. is a plant that was traditionally used as an antipyretic. The activity of this plant can be explained by the presence of the active substance artemisinin, other derivatives like artemether, artemotil, artenimol, artesunate and sodium artesunate, have been developed (Charles et al., 1991; Ferreira et al., 1995). Each has its own physical and pharmaceutical properties, dosage and dosage forms.

In the present study attempts have been made to increase the artemisinin production by treating the plant with Abscisic acid, Gibberellic acid, Methyl jasmonate, acetyl salicylic acid, lead acetate, sodium chloride, and a combination of $\mathrm{GA}_{3}+\mathrm{IAA}$ (gibberellic acid+indole acetic acid).

\section{Materials and methods}

Seeds of $A$. annua (cv. 'CIM-Arogya') were obtanined from CIMAP, Lucknow, India. Seedlings raised in the nursery, were transplanted 40 days after sowing (5-6 leaf stage) at the field of village Ranu of district Vadodara, Gujarat, India. Geographically, Vadodara is situated at $22.49^{\circ} 25^{\prime}$ to $22.49^{\circ} 25^{\prime}$ North latitude and $72^{\circ} .70^{\prime} 74^{\circ}$ to $17^{\prime}$ East Longitude with an altitude of 37.5 meter above 
350

mean sea level.

In Gujarat, Vadodara is located in the middle part, having sub tropical climate with hot dry summer and cool in winter. Vadodara falls in Gujarat plains, hills region (XIII) agro- climatic zone of Gujarat. The mean monthly maximum temperature during April-May varies between $42^{\circ} \mathrm{C}$ to $45^{\circ} \mathrm{C}$. January is the coolest month of the year with an average minimum temperature of $4^{\circ} \mathrm{C}$ and maximum being $15^{\circ} \mathrm{C}$. The Major part of the annual precipitation is received through south-west monsoon from middle of June to September. The average annual rainfall is about 1004 $\mathrm{mm}$. The soil $\mathrm{pH}$ of the site was 8.10.

Plantings were in a randomized complete block design with 3 replications. Plot size was $4.5 \times 4.5 \mathrm{~m}=20.25 \mathrm{~m}^{2}$ with a spacing of $0.30 \times 0.30 \mathrm{~cm}$ between two plants. Distance between two plots was $1 \mathrm{~m}$. The experimental plots were sprayed with different elicitors; concentrations of the treatments are given in Tab. 1. The field was irrigated six times and sprayed three times. Dose of fertilizers Nitrogen, Phosphate, Potassium NPK (150:60:40) kg/h were applied in three splits. Weeding was done twice. The leaves of the treated plants were examined for micromorphological studies. The glandular trichomes of leaves from Artemisia annua (Asteraceae) were examined by light and scanning electron microscopy. The same samples were analyzed for the artemisinin content by HPTLC.

Tab. 1. Effect of growth regulators on artemisinin content and trichome index of $A$. annua

\begin{tabular}{|c|c|c|c|c|}
\hline Treatments & Chemicals & Conc. (mg/l) & $\begin{array}{l}\text { Artemisinin } \\
\text { content (\%) }\end{array}$ & $\begin{array}{l}\text { Trichome } \\
\text { index }\end{array}$ \\
\hline $\mathrm{T} 1$ & $\begin{array}{c}\text { Absicissic } \\
\text { acid }\end{array}$ & $10 \mu \mathrm{M} / \mathrm{lit}$ & 0.88 & 0.073 \\
\hline $\mathrm{T} 2$ & $\mathrm{GA}_{3}$ & $10 \mu \mathrm{M} / \mathrm{lit}$ & 0.81 & 0.053 \\
\hline T3 & $\begin{array}{l}\mathrm{GA}_{3}+ \\
\mathrm{IAA}\end{array}$ & $10 \mu \mathrm{M} / \mathrm{lit}+10 \mu \mathrm{M} / \mathrm{lit}$ & 0.86 & 0.070 \\
\hline T4 & Chitosan & $150 \mathrm{mg} / \mathrm{lit}$ & 0.81 & 0.055 \\
\hline T5 & $\begin{array}{c}\text { Methyl } \\
\text { jasmonate }\end{array}$ & $4.8 \mu \mathrm{M} / \mathrm{lit}$ & 0.94 & 0.128 \\
\hline T6 & $\begin{array}{c}\text { Acetyl } \\
\text { salicylic } \\
\text { acid }\end{array}$ & $1 \mathrm{mM}$ & 0.80 & 0.052 \\
\hline $\mathrm{T} 7$ & $\begin{array}{l}\text { Lead } \\
\text { acetate }\end{array}$ & $500 \mu \mathrm{M} / \mathrm{lit}$ & 0.81 & 0.059 \\
\hline T8 & $\mathrm{NaCl}$ & $160 \mathrm{mM}$ & 0.80 & 0.060 \\
\hline T9 & Nanozime & $1 \mathrm{ml} /$ lit & 0.81 & 0.055 \\
\hline T10 & Control & No spray & 0.78 & 0.049 \\
\hline
\end{tabular}

Light microscopy - Leaves collected from treated and control plots both, were kept in 50\% Jeffrey's solution for one day. The epidermal layers were separated carefully using sharp needles, stained with $1 \%$ safranin and mounted in $50 \%$ glycerin. The sections were observed under light microscope. Microphotograph was taken on (Leica DME) microscope.

Scanning electron microscopy - Fresh samples of leaves were examined under ESEM (Environmental scanning electron microscope) without any processing and photographs were taken.

Artemisinin content - Plant material $(0.1 \mathrm{~g})$ was sonicated with $5 \mathrm{ml} \mathrm{n}$-hexane for $15 \mathrm{~min}$, filtered, evaporated and redissolvedin $1.0 \mathrm{mln}$-hexane and were subjected to HPTLC (CAMAG, SwitzerlandandwinCATSsoft-ware) with
CAMAG TLC Scanner 3 and recoated silica gel Plates 60F 254 (Merck, Germany) with a layer thickness of $0.25 \mathrm{~mm}$ were used.

A stock solution of pure artemisinin (1.0 mg ml-1) was prepared in $n$-hexane and different amount so fit were applied on TLC plates $(20 \mathrm{~cm} \times 20 \mathrm{~cm})$.Chromatography was carried out in a glass TLC tank saturated with the mobile phase n-hexane: diethylether $(1: 1)$ and the plates were developed to a height of about $15 \mathrm{~cm}$. Plates were taken off, dried and spots were visualized by immersing the plates (CAMAG) immersion device in a freshly prepared mixture of glacial acetic acid : concentrated $\mathrm{H}_{2} \mathrm{SO}_{4}$ : anisaldehyde (50:1:0.5), followed by heating of the plates at $110{ }^{\circ} \mathrm{C}$ for $15 \mathrm{~min}$ on aCAMAG TLC plate heater to visualize a pink colour of artemisinin. For quantification, TLC spot, corresponding to artemisinin, was measured at $540 \mathrm{~nm}$. Calibration curve of artemisinin was constructed by plotting concentration versus spot area of the compound (Gupta et al., 1996).

\section{Results}

$A$. annua species possess two types of trichomesglandular and non glandular trichomes (Fig. 1). The large filamenous non glandular trichome, which does not produce essential oil were found abundantly on leaf (Fig. 1). Glandular trichomes were found sparsely throughout the aerial tissue of the plant. The trichome is indented in the epidermis; the cuticle surrounding the apex of the biseriate trichome detaches and forms a sac-like reservoir for essential oil excreted by the apical cells. These trichomes had a bicellular head and a short, cylindrical stalk of different length and features. Most prominent anti-malarial drug artemisinin, a sesquiterpene lactone, is produced in glandular trichomes of $A$. annua.

According to the study, the maximum trichome index was observed in the samples treated with methyl jasmonate (0.128) and minimum in control (0.049) (Fig. 1e, 1j). Treatments of $\mathrm{GA}_{3}$ (Fig. 1b), Chitosan (Fig. 1d), Lead acetate (Fig. 1g) and Nanozime (Fig. 1i) showed a very less difference (Tab. 1). Whereas treatments with acetyl salicylic acid (Fig. 1f) and sodium chloride (Fig. 1h) recorded the lowest trichome index over control.

HPTLC analyses for Artemisinin (\%) content also followed the same pattern, where samples treated with methyl jasmonate were having higher artemisinin content followed by the treatments of Abscissic acid and $\mathrm{GA}_{3}+\mathrm{IAA}$. Treatments of $\mathrm{GA}_{3}$, Chitosan, Lead acetate, Nanozime, Acetyl salicylic acid and sodium chloride were with comparatively low percentage.

Artemisinin immunolocalization has not been achieved, but still there is a strong circumstantial evidence that the compound is sequestered in the glandular trichomes. Duke et al. (1994) described the development of such glands in leaves of $A$. annua and reported that neither artemisinin nor artemisitene were detected from a glandless biotype and that virtually all artemisinin could be extracted by a 5-sec leaf dip in chloroform, without visible damage to other leaf epidermal cells, from the biotype with glands. This suggests the trichome density is directly proportional to the artemisinin content.

Results showed that the application of methyl jasmonate to $A$. annua leaves induced increased densities of glandular trichomes on new leaves expanding after treatments. 

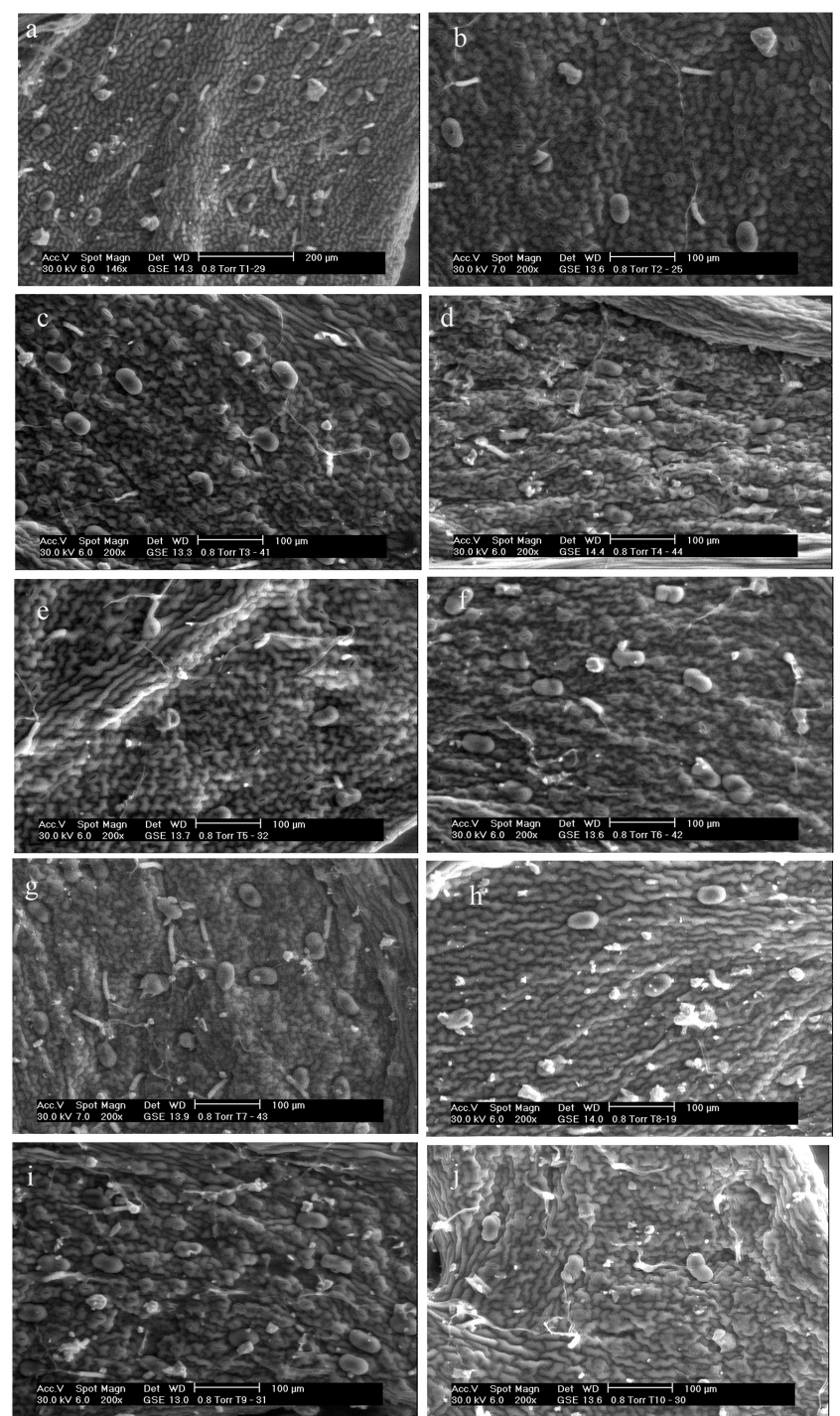

Fig. 1. (a-h)-Ventral leaf surface with glandular and nonglandular trichomes. a.-T1- treatment with absicissic acid; b.T2- treatment with GA3; c.-T3- treatment with GA3+IAA; d.-T4- treatment with chitosan; e.-T5- treatment with methyl jasmonate; f.-T6- treatment with acetyl salicylic acid; g.-T7treatment with lead acetate; h.-T8- treatment with $\mathrm{NaCl}$; i.T9- treatment with Nanozime; J.-T10- control

The highest densities of trichomes were present on leaves produced 110 th day after methyljasmonate treatment. Trichome densities were twice higher in methyl jasmonate than in control treated plants.

Also the artemisinin content of these samples was the highest. Other applications also recorded the trichome initiation along with the artemisinin content. The next highest artemisinin content was found in Absicissic acid and $\mathrm{GA}_{3}+\mathrm{IAA}$ with corresponding trichome index. Application of $\mathrm{GA}_{3}$, Chitosan, Lead acetate and Nanozime promoted the trichome initiation in a common manner and simultaneously the artemisinin content. It was found that acetylsalicylic acid and $\mathrm{NaCl}$ had the least effect on trichome formation and the artemisinin content compared with control.
Relation between Trichome density and Artemisinin Content

The Pearson's Correlation coefficient between Trichome density and Artemisinin content is 0.93 and the $95 \%$ Confidence Interval for it is $(0.89,0.95)$. Test of hypothesis to determine significance of the relationship (Ho: $r=0)$ gives the

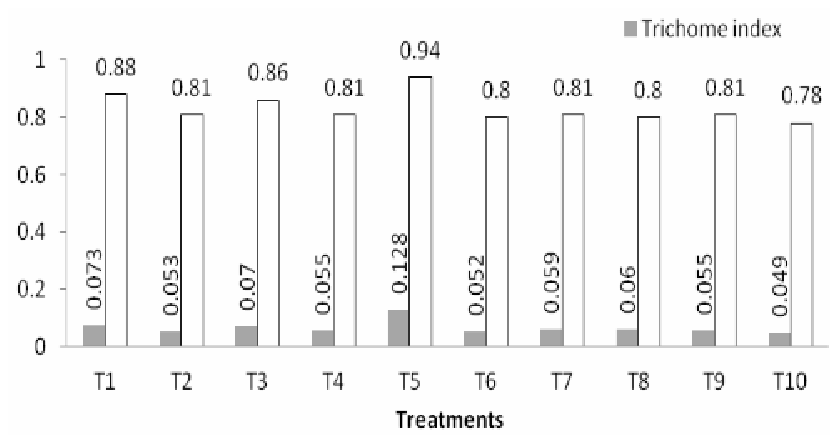

Fig. 2. Treatments $\mathrm{T} 1$ to $\mathrm{T} 10$ and corresponding Trichome index and artemisin content (\%)

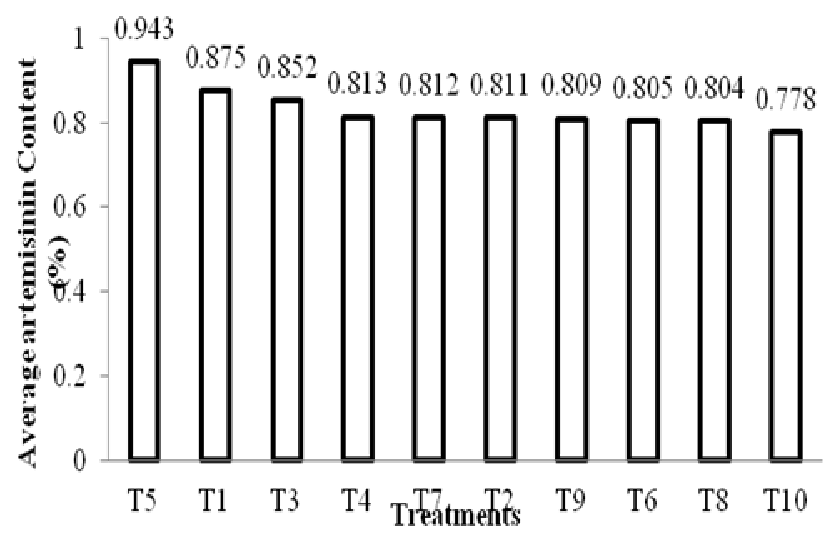

Fig. 3. Mean artemisinin content

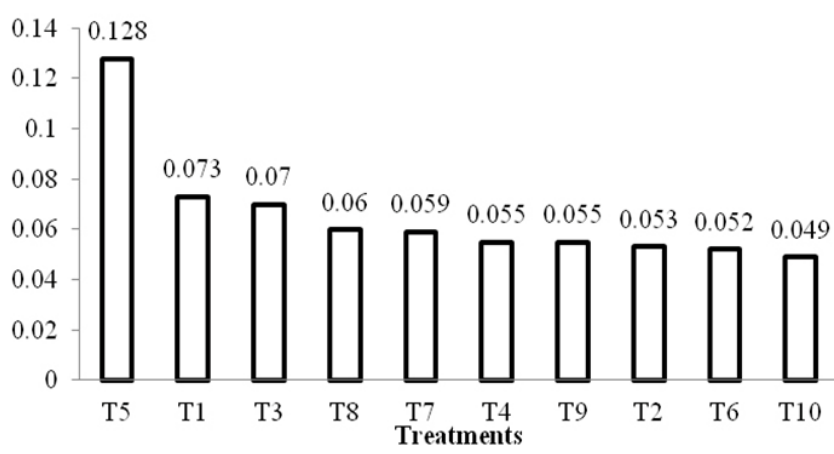

Fig. 4. Mean trichome density

$\mathrm{p}$-value $<0.001$ for $\mathrm{t}$-test with degrees of freedom 98. And the Spearman's Rank Correlation Coefficient is 0.7 with $95 \%$ CI $(0.64,0.82)$. The t-test yields p-value $<0.001$ with 98 degrees of freedom. So, we can say that there is a strong positive relationship between Trichome density and Artemisinin content.

The figure 4 shows that Methyl Jasmonate is exceptionally effective treatment with highest average Trichome density and 
352

Control treatment is the lowest effective. Absicissic Acid and $\mathrm{GA}_{3}+\mathrm{IAA}$ are moderately effective treatments.

No treatment is significantly skewed or having kurtosis also the coefficient of variation is very small for all the treatments.

All the treatments are significantly effective as compared to Control group. However, Methyl Jasmonate could be a potential treatment for greater artemisinin production and for that matter Absicissic Acid and $\mathrm{GA}_{3}+\mathrm{IAA}$ are also good treatments.

\section{Discussion}

Although some authors reported artemisinin being highest during preflowering stages (Woerdenbag et al., 1994), others reported artemisinin reaching its peak during flowering (Singh et al., 1988; Laughlin, 1995).

Reports on the distribution of artemisinin throughout the plant have been inconsistent. During the life cycle of a leaf, artemisinin was always present. Quantities were low at leaf appearance and increased steadily. The number of mature, capitate trichomes on the adaxial leaf side increased after leaf appearance until the end of leaf expansion, and then decreased, probably due to collapse of trichomes. Artemisinin production thus occurred when trichomes were collapsing. Later formed leaves achieved higher concentrations of artemisinin than earlier formed leaves, because of a higher trichome density and a higher capacity per trichome.

Plant trichome initiation depends upon the diverse developmental and environmental conditions. In this study, all treatments promoted trichome initiation. As it is known that the artemisinin is secreted in glandular trichome, the trichome density directly corresponds to the percent artemisinin content (Chart 1). So, higher the trichome number, higher will be the artemisinin content.

We studied the effect of all exogenous treatment on leaf trichome formation and found the general ability of phytohormones to impinge on trichome initiation. The most effective phytohormone found was methyl jasmonate which activated the formation of large numbers of glandular trichomes.

Elicitors are natural compounds that have shown far reaching effects on the growth and development of plants even at low concentration (Arshad and Frankenberger, 1998). Plant growth regulators are known to affect growth, flowering and assimilate translocation in plants (David $e t$ al., 1985; Hayat et al., 2001) Auxins, gibberellins ( $\left(\mathrm{GA}_{3}\right)$ and kinetin being well known plant growth promoting hormones have shown to be involved in a variety of plant growth and development processes (Frankenberger and Arshad, 1995).

Attempts to increase artemisinin production by adjusting the nutrients, hormones, growth conditions, elicitors, and stresses are reported (Qian et al., 2007; Ferreira et al., 2005; Wang et al., 2002). Previous research has identified an important role for the hormone gibberellin, in constitutive trichome production in Arabidopsis (Perazza et al., 1998). Phytohormones are also known to modulate epidermal differentiation programs (Maes et al., 2008).

One of the study demonstrated, both $\mathrm{NaCl}$ and lead induce oxidative stress in $A$. annua plants and that of the stress is proportional to the concentration of the stressor.
The oxidative stress in turn alters artemisinin concentration and yield. But here the artemisinin content and trichome density has a minimum effect after applying $\mathrm{NaCl}$. Studies on salicylic acid shows reduction in trichome density and number and when treated with jasmonic acid it showed the largest increase in trichome density and number (Traw and Bergelson, 2003). Similar results were found in the present study. In addition, the application of $\mathrm{GA}_{3}$ was effective in the increasing the content and trichome density as compared to control. According to Farooqi et al. (1994) a positive effect of $\mathrm{GA}_{3}$ on secondary product production of alkaloids and diosgenin has been reported.

\section{Conclusions}

The substantial increase in artemisinin yield following the applications of elicitors to plants after 20 weeks transplating may be attributed to the favorable effect of these chemicals and growth regulators on the growth and trichome formation.

\section{References}

Abdin MZ, Israr M, Rehman RU, Jain SK (2003). Artemisinin, a novel antimalarial drug biochemical and molecular approaches for enhanced production. Planta Med 69:289-299.

Arshad M, Frankenberger WT Jr (1998) Plant growth regulating substances in the rhizosphere. Microbial production and functions. Advances in Agronomy 62:45151.

Bhakuni RS, Jain DC, Sharma RP, Kumar S. (2001) Secondary metabolites of Artemisia annua and their biological activity. Curr Sci 80:35-48.

Charles DJ, Cebert E, Simon JE (1991) Characterization of the essential oil of Artemisia annua L. J Essent Oil Res 3:33-39.

Cutler DF (1969). Juncales. In: Anatomy of the Monocotyledons. Metcalfe CR (Ed.). Clarendon Press, Oxford.

Law DM, Hamilton RH (1985). Effects of Gibberellic Acid on Endogenous Indole-3-Acetic Acid and Indoleacetyl Aspartic Acid Levels in a Dwarf Pea. Plant and Cell Physiology 26(4):615-625.

Duke MV, Paul RN, Elsohly HN, Sturtz G, Duke SO (1994). Localization of artemisinin and artemisitene in foliar tissues of glanded and glandless biotypes of Artemisia annua L. Int J Plant Sci 155:365-372.

Duke SO, Paul RN (1993). Development and fine structure of the glandular trichomes of Artemisia annua L. International Journal of Plant Sciences 154(1):107-118.

Farooqi AH, Shukla YN, Sharma S, Bansal RP (1994). Relationship between Gibberellin and Cytokinin activity and flowering in Rosa damascena Mill. Plant Growth Regulat 14:109-113.

Ferreira JF, Simon JE, Janick J (1995). Developmental studies of Artemisia annua: flowering and artemisinin production 
under greenhouse and field conditions. Planta Med 61:167-170.

Ferreira JF, Simon JE, Janick J (1997) Artemisia annua: botany, horticulture, pharmacology. In: Horticultural reviews (Janick J ed.). New York, NY: John Wiley and Sons, Inc. pp. 319-371.

Ferreira JFS, Laughlin JC, Delabays N, de Magalhaes PM (2005). Cultivation and genetics of Artemisia annua L. for the increased production of the antimalarial artemisinin Plant Gen. Resources 3:206-229.

Frankenberger WT Jr, Arshad M (1995). Phytohormones in Soil: Microbial Production and Functions. Marcel Dekker Inc. New York, USA. 503p.

Gupta MM, Jain DC, Verma RK, Gupta AP (1996). A rapid analytical method for the estimation of artemisinin in Artemisia annua. J Med Aromat Plant Sci 18: 5-6.

Hayat S, Ahmad A, Hussain A, Mobin M (2001). Growth of wheat seedlings raised from the grains treated with $28-$ homobrassinolide. Acta Physiol Plant 23:27-30.

Klayman DL (1985). Qinghaosu (Artemisinin): an antimalarial drug from China. Science 228:1049-1055.

Klayman DL (1993). Artemisia annua: from weed to respectable antimalarial plant. In: Kinghorn, Balandrin MF (eds.). Human Medicinal Agents from Plants. Am Chem Soc Symp Series, Washington, DC, USA.

Klayman DL (1989). Weeding out malaria. Nat Hist 3:18-26.

Laughlin JC (1995). The influence of distribution of antimalarial constituents in Artemisia annua L. on time and method of harvest. Acta Hort 390:67-73.

Maes L, Inzé D, Goossens A (2008). Functional specialization of the transparent testa glabral network allows differential hormonal control of laminal and marginal trichome initiation in Arabidopsis rosette leaves. Plant Physiol 148:1453-1464.
Qian Z, Gong K, Zhang L, Lv J, Jing F, Wang Y, Guan S, Wang G, Tang K (2007). A simple and efficient procedure to enhance artemisinin content in Artemisia annua L. by seeding to salinity stress. African J Biotechnol 6:14101413.

Singh A, Vishwakarma RA, Husain A (1988). Evaluation of Artemisia annua strains for higher artemisinin production. Planta Med 54:475-476.

Traw BM, Bergelson J (2003). Interactive effects of jasmonic acid, salicylic acid, and gibberellinon induction of trichomes in Arabidopsis. Plant Physiol 133:1367-1375.

Turner GW, Croteau R (2004). Organization of monoterpene biosynthesis in Mentha. Immunochemical localizations of geranyl diphosphate synthase, limonene-6-hydroxylase, isopieritenol dehydrogenase, and pulegone reductase. Plant Physiol 136(4): 4215-27.

Wang ZQ, Ribnicky D, Zhang XH, Zuberi A, Raskin I, et al. (2011). An extract of Artemisia dracunculus L. enhances insulin receptor signaling and modulates gene expression in skeletal muscle in KK-A(y) mice. J Nutr Biochem 22:7178.

Wang JW, Xia ZH, Tan RX (2002). Elicitation on artemisinin biosynthesis in Artemisia annua hairy roots by the oligosaccharide extract from the endophytic Colletotrichum sp. B501. Acta Bot Sinica 44:1233-1238.

Woodenbag HJ, Pras N, Chan NG, Bang BT, Bos R, Vand Uden W, Van YP, Bo NV, Batterman S, Lugt CB (1994). Artemisinin, related sesquiterpenes, and essential oil in Artemisia annua during a vegetative period in Vietnam. Planta Med 60:272-275. 